Hegemonia - Revista Eletrônica de Relações Internacionais do Centro Universitário Unieuro ISSN: $1809-1261$

UNIEURO, Brasília, número 20, Janeiro-Junho de 2017, pp. 148-161.

Recebido em: 14/11/2016

Avaliado em: 2/12/2016

Aprovado em: 23/12/2016

\title{
Da Teoria da Estruturação às Reflexões sobre a Modernidade e Democracia: Uma Breve Visão sobre a Construção do Pensamento Intelectual de Anthony Giddens
}

\author{
Manoel Santana Cardoso ${ }^{1}$
}

Resumo: O ensaio busca realizar uma breve revisão da trajetória intelectual do sociólogo Anthony Giddens, destacando os aspectos mais importantes de sua produção teórica e as repercussões desta no interior da teoria sociológica contemporânea. Ao mesmo tempo, promover uma reflexão sobre a proposta do autor em construir novas abordagens no campo da teoria sociológica. Dono de uma das mais prolíficas produções no campo da sociologia, Giddens desenvolveu, ao longo de 30 anos de atividade, uma ampla discussão que o coloca como um dos mais importantes teóricos em atividade nos dias atuais. Seus trabalhos contemplam aspectos de amplo interesse, tais como a discussão sobre o papel da sociologia, bem como do sociólogo, em nossa sociedade, a partir da abordagem de temas que vão desde questões de ordem mais política, quanto aquelas que tratam da temática da globalização e suas consequências sobre o indivíduo, a família ou mesmo as relações íntimas. Democracia e alternativas aos modelos políticos vigentes são, também, temas de seu interesse. $\mathrm{O}$ trabalho volta-se para o entendimento entre as novas realidades, determinadas pelas redes sociais, as quais um novo sentido para o conceito de comunidade. O que ora vemos e aceitamos como "comunidade", diz respeito muito mais a grupos de interesse, nos quais as relações sociais se estabelecem e se desconfiguram ao sabor da velocidade da time line do Facebook. O descompasso entre as redes e a vida real, transformou as primeiras em espaços onde o narcisismo abriu espaço para uma cultura do ódio e da intolerância. Neste cenário, construiu-se um novo espaço para a discussão, a conceituação e a vivência da democracia. Deve-se questionar, se haveria aqui espaço para o indivíduo reflexivo preconizado por Giddens, sabedor e conhecedor de sua realidade social e política.

Palavras-chave: Giddens, Teoria Sociológica, Democracia, Redes Sociais

\footnotetext{
${ }^{1}$ Antropólogo: Doutor em Sociologia (UnB); professor do Mestrado em Ciência Política do Centro Universitário Euro-Americano.
} 
Abstract: The essay gives a brief review of the intellectual trajectory of sociologist Anthony Giddens, highlighting the most important of his theoretical production and its repercussions within the contemporary sociological theory. At the same time, it promotes a reflection on the author's proposal to construct new approaches in the field of sociological theory. Author of one of the most prolific productions not in the field of sociology, Giddens has developed, over 30 years of activity, a broad discussion that points out as one of the most important theorists in active today. His works contemplate questions such as discussion about the role of sociology in our society, from the approach of issues that are of more political issues, as well as those that deal with globalization and its consequences on the individual, the family or even as relations Intimate Democracy and alternatives to prevailing political models are also subjects of interest. What we now see and accept as "community," relates much more to interest groups, in which social relationships are shaping up and deconstructing themselves in the taste of Facebook's timeline speed. The mismatch between networks and a real life has turned into spaces where narcissism has opened space for a culture of hatred and intolerance. In this scenario, a new space has been built for a debate, a conceptualization and an experience of democracy. It must be questioned whether there would be room here for the reflexive individual advocated by Giddens, well-known and knowledgeable of his social and political reality.

Key-words: Giddens; Sociological Theory; Democracy; Social Medias.

\section{i. Introdução}

O presente ensaio cumpre precipuamente duas funções. A primeira delas busca realizar uma breve revisão da trajetória intelectual do sociólogo britânico Anthony Giddens, destacando os aspectos mais importantes de sua produção teórica e as repercussões desta no interior da teoria sociológica contemporânea. Em segundo lugar, promover uma reflexão sobre a proposta daquele autor em construir novas abordagens no campo da teoria sociológica e avaliar em que medida tal objetivo foi, ou está sendo, alcançado, mais especificamente no que tange aos alcances desta proposta na esfera política. Dono de uma das mais prolíficas produções no campo da sociologia, Giddens desenvolveu, ao longo de 30 anos de atividade, uma ampla discussão que o coloca como um dos mais importantes teóricos em atividade nos dias atuais. Seus trabalhos contemplam aspectos de amplo interesse, tais como a discussão sobre o papel da sociologia, bem como do sociólogo, em nossa sociedade, a partir da abordagem de temas que vão desde questões de ordem mais política, quanto aquelas que tratam da temática da globalização e suas conseqüências sobre o indivíduo, a família ou mesmo as relações íntimas. Democracia e alternativas aos modelos políticos vigentes são, também, temas de seu interesse. 
Neste sentido, desenvolvemos nossa análise a partir de dois momentos distintos. Primeiramente, destacamos o modo como Anthony Giddens inicia sua carreira propondo-se a uma revisão das análises feitas sobre a modernidade pelos três "pais fundadores" da sociologia: Marx, Durkheim e Weber, o que vem a ser feito de forma mais intensa na obra Capitalismo e Moderna Teoria Social (1971), e, em menor escala, em trabalhos subsequentes. Posteriormente, o autor vai construir seus próprios pontos de vista em relação à modernidade e à sociedade capitalista, fazendo, em parte, uma crítica a estes fundadores. Esta etapa de seu pensamento é mais representativamente demarcada em As Novas Regras do Método Sociológico (1976), Central problems in social theory: action, sutructure and contraditions in social analysis (1979), e por A Constituição da Sociedade, de 1984. Posteriormente, o processo de evolução do pensamento de Giddens vai levá-lo a um aprofundamento das análises sobre a modernidade e a "radicalização" desta, com um conseqüente reordenamento de noções como tempo e espaço, por exemplo. Esta fase é inaugurada por As Conseqüências da Modernidade (1990), e vai se afirmando como a grande temática na atualidade da obra de Giddens, ocupando um importante espaço em toda a sua produção científica recente.

Não obstante a ampla repercussão de sua obra e o fato de Giddens ser hoje um dos teóricos mais lidos no campo da sociologia e da filosofia política, o autor não é uma unanimidade entre os cientistas sociais e seus trabalhos são, por vezes, objeto de duras críticas. Estas, em geral, alegam que suas análises seriam pouco aprofundadas e que o autor não se atém por muito tempo a uma única temática. Por nosso turno, entendemos que Anthony Giddens deve ser visto como um teórico que tem trazido para a disciplina temas diretamente afeitos à vida do indivíduo nestes tempos de uma radicalizada modernidade. Lembremos, sua obra é inconclusa, aberta, portanto, a novos caminhos e a novos entendimentos.

\section{ii. A construção de uma teoria sociológica}

Capitalismo e Moderna Teoria Social representa uma bem sucedida tentativa de Giddens em fazer renascer os clássicos da sociologia no contexto da disciplina. A partir da desconstrução das idéias de Marx, Durkheim e Weber, surge como uma alternativa ao ideário sobre tais autores então predominante, com reconhecida origem na corrente sociológica 
americana, principalmente, a partir dos trabalhos de Talcott Parsons ${ }^{2}$. Giddens defende a importância dos três autores abordados em função de terem eles definido, do ponto de vista sociológico, aquelas que seriam as características fundamentais do nascente sistema capitalista, bem como da sociedade moderna, em oposição às formas e estatutos sociais anteriormente vigentes $^{3}$. O trabalho, porém, não se constitui em uma síntese acrítica, em relação aos clássicos. Em verdade, Giddens, não obstante a importância que confere a estes, os vê como tendo desenvolvido análises parciais e incompletas e, portanto, tendo em vista principalmente as questões presentes na alta modernidade, merecedoras de novas abordagens. Capitalismo e Moderna Teoria Social é uma obra de fôlego e, não obstante os inúmeros trabalhos posteriores à sua publicação, ainda representa uma das mais consistentes análises desenvolvidas sobre os clássicos ${ }^{4}$. Na continuidade das análises nele contidas, o autor vai lançar as bases de sua própria visão sobre o campo teórico da sociologia, que tem seu ápice em A Constituição da Sociedade (1984), onde desenvolve sua teoria da estruturação, uma de suas mais importantes contribuições às ciências sociais. Na sequência, Capitalismo e Moderna Teoria Social afirma a centralidade de Ėmile Durkheim na obra de Giddens, principalmente nas duas primeiras fases. Diz Giddens (2000),

O que tentei fazer em Capitalism and modern social theory foi por a obra de Durkheim contra o pano de fundo do desenvolvimento da sociedade moderna. A maioria dos que escreveram sobre ele não fez isso realmente. Interessavam-me, em particular, sua análise do advento do individualismo moderno, a relação deste com a desigualdade, a questão da solidariedade e a transição entre duas formas de solidariedade. Todas estas questões ainda hoje são pertinentes.

O interesse pelos clássicos, Durkheim particularmente, vai levar Giddens a ver no estruturalismo as condições que favorecem a construção de uma importante ferramenta teórica. Com efeito, a teoria da estruturação é um dos momentos mais importantes e férteis da sociologia de Anthony Giddens. Trata-se de uma elaboração teórica que tem início em seu

${ }^{2}$ GIDDENS, A. \& PIERSON, C. Conversas com Anthony Giddens: o sentido da modernidade. Rio de Janeiro, Editora FGV, 2000, pág, 14.

${ }^{3}$ GIDDENS, A. Capitalismo e Moderna Teoria Social. Lisboa, Editorial Presença, 1994, pág. 23.

${ }^{4} \mathrm{O}$ texto não chega a rivalizar com As Etapas do Pensamento Sociológico, de Aron, mas pode ser uma boa complementação e, mesmo, um contraponto a este.

${ }^{5}$ GIDDENS, A. \& PIERSON, C., Op Cit. 
trabalho The New Rules of Sociological Method (1976), avança em Central Problems in Social Theory (1979) e vai se consolidar em A Contemporary Critique of Historical Materialism (1981) e The Constitution of Society (1984). Já a partir de 1985, a teoria da estruturação direciona-se às análises das questões referentes ao Estado e à violência estatal na obra The nation State and violence. É neste momento que as reflexões de Giddens passam a privilegiar o "moderno" e outros conceitos que lhe são correlatos (reflexividade e risco), e, mais posteriormente, vão embasar os seus escritos políticos.

Em termos sintéticos, a teoria da estruturação busca dar conta de aspectos da realidade social até então não abordados, tanto pelo funcionalismo quanto pelo estruturalismo, e que contemplam "uma nova tipologia dos sistemas sociais enquanto ajustes entre relações de tempo-espaço ...". Para Giddens, as análises funcionalista e estruturalista apresentam semelhanças na ênfase fortemente colocada na "preeminência do todo social sobre suas partes individuais (isto é, seus atores constituintes, sujeitos humanos)" (1989, 1). Tal proeminência contempla uma primazia da estrutura, com uma acentuação de suas qualidades restritivas, em relação à ação. A isto, Giddens vai opor uma visão que coloca as práticas sociais ordenadas no tempo e no espaço (recursivas), como sendo o domínio básico de estudo das ciências sociais.

As atividades sociais humanas, à semelhança de alguns itens auto-reprodutores na natureza, são recursivas. Quer dizer, elas não são criadas por atores sociais, mas continuamente recriadas por eles mesmos através dos próprios meios pelos quais eles se expressam como atores $(1989,2)$.

Para Giddens, os agentes humanos são dotados de uma cognoscitividade que os leva a uma ordenação recursiva das práticas sociais. Este mecanismo está associado a uma reflexividade que somente é possível devido a uma continuidade de tais práticas no decorrer do tempo e do espaço. "Ser um ser humano", diz, "é ser um agente intencional ...", o qual se define pela sua capacidade de informar de modo reflexivo sobre as razões que os direcionam em suas ações, em um fluxo contínuo. Existe, portanto, para o autor, uma consciência prática que pode ser observada no agente, tanto em sua atuação individual quanto na atuação em contexto em que se encontrem outros atores.

${ }^{6}$ Idem. 
O conbecimento de convençoes sociais, de si mesmo e de outros seres bumanos, pressuposto na capacidade de "prosseguir" na diversidade de contextos da vida social, é detalhado e impressionante. Todos os membros competentes da sociedade são imensamente talentosos nas realizações práticas de atividades sociais e hábeis "sociólogos". (Giddens').

É inegável que Giddens exibe uma forte influência do estruturalismo francês, notadamente das idéias de Lévi-Strauss, e daí o fato do autor travar um diálogo, também bastante próximo e instigante, com a linguística de Saussure (1857-1913). Em alguma medida, tal estratégia o afasta da sociologia inglesa, abordando conceitos e pontos de vista mais recorrentes na escola francesa. Isto também estaria mais de acordo com seus estudos iniciais em psicologia, realizados na Universidade de Hull. Assim, observamos uma imanente preocupação com a relação entre o indivíduo e a estrutura e entre ação e estrutura, desembocando em um franco enriquecimento de tais conceitos. Contudo, distintamente do modo como pensavam os estruturalistas, Giddens não vê a sociedade como tendo a mesma natureza que a linguagem. Referindo-se a esta questão, afirma:

... a linguagem tem estrutura, tem forma, mas não é visivel e só existe na medida em que faz parte de nossas ações quando a utilizamos diariamente. Isso é o que eu chamo de propriedade recursiva da linguagem. Não sustento que a sociedade "é como a linguagem", como diriam os estruturalistas; mas a linguagem nos fornece alguns indícios de como a recursividade se processa. Pode-se entender a "sociedade" como um complexo de práticas recorrentes que criam instituições. Tais práticas dependem dos hábitos e modos de vida adotados pelos indivíduos. Não só eles as "utilizam” em sua atividade, como também essas práticas de vida constituem a própria atividade.

É em As Conseqüências da Modernidade (1990), que Giddens qualifica o seu conceito de modernidade, desenvolvendo uma análise por ele qualificada como cultural e epistemológica $(11)^{8}$. Sua visão da modernidade é expandida ao extremo, contemplando uma alteração em relação às variáveis que nela classicamente se incluem. Até então, entre outras realidades, a modernidade refere-se a um tempo e espaços objetivamente definidos: Europa/Ocidente, séculos XIX e XX. Para Giddens, o momento histórico que ora vivemos evoca uma nova

${ }^{7}$ GIDDENS, A. A Constituição da Sociedade. Martins Fontes, São Paulo, 1989, p. 20.

${ }^{8}$ GIDDENS, A. As Conseqüências da Modernidade. São Paulo: Ed. Unesp, 1991. 
formatação dessas categorias, as quais tornam-se mais voláteis e algo fluidas, assim como defendido por Baumann? . Vivemos sob a égide da alta modernidade e isto representa novas e importantes implicações para o indivíduo.

A alta modernidade, ou modernidade radicalizada, configura-se como um período no qual as estruturas sociais instituídas a partir do surgimento do modo de produção capitalista vão se acirrando, em oposição a uma cultura mais tradicional. Trata-se de uma visão que se configura a reboque da natureza reflexiva do indivíduo nas sociedades contemporâneas. Reflexividade, neste caso, seria a capacidade que tem os atores sociais de verbalizarem sobre o conteúdo e significado de suas ações. Em tempo, esta visão de um indivíduo/ator consciente das razões de suas ações está presente na obra de Giddens já desde A Constituição da Sociedade.

Longe, no entanto, de oferecer ao indivíduo mais tranqüilidade, a reflexividade o coloca diante de uma sociedade cuja marca mais evidente é o risco. Esse tempo, por alguns associado à pós-modernidade, caracteriza-se pela diluição da "grand narrative" $e^{10 ",}$, deitando por terra as possibilidades de um futuro previsível para a humanidade. Conseqüência desta condição, o indivíduo percebe-se sem o controle dos mecanismos que regem sua existência.

A desorientação que se expressa na sensação de que não se pode obter conbecimento sistemático sobre a ordem social, devo argumentar, resulta em primeiro lugar, da sensação de que muitos de nós temos sido apanhados num universo de eventos que não compreendemos plenamente, e que parecem em grande parte estar fora de nosso controle. Para analisar como isto veio a ocorrer, não basta meramente inventar novos termos, como pós-modernidade e o resto. Ao invés disso, temos que olhar novamente para a natureza da própria modernidade a qual, por certas razões bem especificas, tem sido insuficientemente abrangidas, até agora, pelas ciências sociais (12).

É no campo da filosofia política Anthony Giddens guarda algumas de suas recentes preocupações e avança de modo significativo nas reflexões quanto ao papel da democracia na vida das sociedades contemporâneas. Em Para Além da Esquerda e da Direita (1996) ${ }^{11}$, o autor discute a constituição dos sistemas políticos no mundo atual e, de maneira particular, o

\footnotetext{
${ }_{9}^{9}$ BAUMAN, Z. O Mal-Estar da Pós-Modernidade. Rio de Janeiro, Jorge Zahar Editor, 1998.

${ }_{10}$ Aqui, Giddens faz referência à obra de Lyotard, The Post-Modern Condition (Minneapolis: Univessity of Missesota Press, 1985). No Brasil, A Condição Pós Moderna, Rio de Janeiro, José Olympio Editora, 2002.

11 GIDDENS, Anthony. Para Além da Esquerda e da Direita. São Paulo, Editora UNESP, 1996.
} 
surgimento de um novo cenário no qual conceitos, há muito estabelecidos, passam por uma revisão à luz das novas realidades sociais. Assim como Bobbio, Giddens vê o surgimento deste novo cenário de modo algo otimista embora considere que há ainda muito a fazer e conquistar.

O conceito de democracia defendido por Giddens vai ao encontro daquele definido por outros autores, notadamente Weber e Bobbio, conforme é explicitamente admitido.

A democracia liberal, admito, concordando com Weber e Bobbio, é basicamente um sistema de representação. É uma forma de governo caracterizada por eleições regulares, sufrágio universal, liberdade de consciência e pelo direito universal de candidatar-se a um cargo ou de formar associações políticas. Definida desta maneira, a democracia é normalmente relacionada ao pluralismo e à expressão de interesses diversos (idem, 129).

$\mathrm{Na}$ definição que acima reproduzimos, são nossos os grifos nas expressões associações políticas, pluralismo e interesses diversos. São eles os pontos que consideramos importantes na seqüência do pensamento de Giddens em relação ao futuro da democracia e dos regimes democráticos, não obstante seu alerta quanto ao fato de que esta forma de governo ainda representa a hegemonia de grupos distantes do eleitor comum e dominada e com freqüência por insignificantes questões de política partidária (idem). A insistência de Giddens quanto à existência de uma ordem social cada vez mais reflexiva (132), direciona o pensamento do autor rumo ao que ele vai denominar de democracia dialógica. Esta seria uma evolução das democracias deliberativas, assim como definidas por Miller $(1992)^{12}$, e baseadas em uma ampliação do conceito de democracia no interior de duas ordens nas quais Giddens observa que "nossas vidas" estão de modo mais significativamente sendo alteradas: "a vida cotidiana, por um lado, e os sistemas globalizadores, por outro" (132). É a partir da análise nas alterações e interações entre duas ordens que Giddens desenvolve sua discussão.

Qual o conceito de democracia dialógica? Quais seus pressupostos? Percebemos um humanismo quase iluminista na concepção do que esta venha a ser. Coerente com sua visão de um ator social reflexivo, sujeito de suas ações e apto a intervir na ordem social, Giddens aposta na capacidade do indivíduo em atuar no interior da sociedade de modo a construir uma ordem política que esteja mais adequada às suas necessidades, mas que também é reflexo das

12 MILLER, D. Deliberative Democracy and Social Choice. Political Studies, August 1992, Vol. 40, N. 1, 54-67. 
condições verificadas no mundo atual. O autor reivindica, por exemplo, alguma influência das comunicações eletrônicas como fator importante em mudanças recentes na ordem política mundial, notadamente aquelas que varreram o leste europeu a partir de $1989^{13}$. Ainda considerando este fator, é ele que vai fornecer os mecanismos que promovem uma maior interação entre os indivíduos pertencentes às muitas culturas existentes no mundo e que passam a conviver de modo mais aproximado. Portanto, a democratização pressupõe, para Giddens, uma aceitação que se exercita por meio da comunicação, do diálogo entre grupos e entre as culturas.

A democracia dialógica não é a mesma coisa que uma situação ideal de discurso. Em primeiro lugar, a democratização dialógica não está ligada a um teorema filosófico transcendental. Não pressuponho, como faz Habermas, que essa democratização esteja de alguma forma implicada pelo próprio ato da fala ou pelo diálogo. O potencial para a democracia dialógica está, em vez. disso, presente na difusão da reflexividade social como uma condição tanto das atividades diárias como da persistência de formas mais amplas de organização coletiva. Em segundo lugar, a democracia dialógica não é necessariamente orientada para a obtenção de consenso. ... A democracia dialógica pressupõe apenas que o diálogo em um espaço público fornece um modo de viver com o outro em uma relação de tolerância (grifo do autor) mútua - seja esse "outro" um indivíduo ou uma comunidade global de fiéis religiosos. (Giddens, 1996, 133).

iii. Alternativas ao "mundo em descontrole"

Onde, portanto, devemos nos voltar no sentido de observar as possibilidades de uma democracia dialógica, no sentido preconizado por Giddens? Segundo o autor, em quatro áreas interligadas, onde tendências democratizadoras favoreceriam uma possibilidade de renovação do radicalismo politico. Seriam elas, a arena da vida pessoal, os movimentos sociais e os grupos de auto-ajuda, a arena organizacional e, por fim, a ordem global maior. $\mathrm{Na}$ arena da vida pessoal, Giddens identifica a possibilidade de construção de novos formatos de relacionamento, baseado em uma confiança

\footnotetext{
${ }^{13}$ É inegável o papel das redes sociais no novo ativismo político, com suas consequências bastante observáveis. A eleição de Barack Obama como presidente dos Estados Unidos em 2008 e o uso intensivo que fez das mídias sociais tornou-se um case vastamente estudado. Há que se alertar, contudo, para o que riscos que nos informa Bauman, em recente entrevista, quando alerta que as redes sociais são armadilhas (http://brasil.elpais.com/brasil/2015/12/30/cultura/1451504427_675885.html).
} 
mútua, por ele chamados de relacionamentos puros, "aquele que se estabelece e se mantém por si só - pelas recompensas que a associação com o outro, ou com os outros, pode trazer” (135). O campo das relações sexuais, a família e o casamento seriam os espaços onde o relacionamento puro poderia atuar de modo a permitir o surgimento de uma confiança mútua, ativa, entre os indivíduos.

Embora perceba que os movimentos sociais e grupo de auto-ajuda não sejam necessariamente democráticos em seus objetivos, eles representam para Giddens instrumentos importantes na constituição de uma "reflexividade intensificada da vida global e local', tendo em vista o fato de abrirem espaços para o diálogo sobre questões de interesse para as coletividades. A importância de tais grupos fica evidente quando observamos a atuação dos movimentos ambientalistas e de defesa dos direitos das mulheres, dos homossexuais e de algumas minorias étnicas, por exemplo.

Em Modernidade e Identidade (1999), Giddens está preocupado em estabelecer os novos mecanismos de auto-identidade que são constituídos pelas instituições da modernidade, mas que também as constituem (9). A modernidade estabelece condições de existência amplamente distintas daquelas que podiam ser observadas nas sociedades pré-modernas e isto tem conseqüências diretas ao nível pessoal/individual, ao mesmo tempo que coletivo/social. Num plano de fundo, busca-se discutir o processo de despolitização observável nas sociedades contemporâneas, o qual tem suas causas em razões de ordem estrutural. Para dar conta de tais mudanças, Giddens promove uma incursão nos modelos de relações pessoais e coletivas que são determinados pela alta modernidade, identificando aí, algumas transformações, que são determinadas de modo direto pela descontinuidade verificável entre as instituições modernas e os modos de vida prémodernos. Um importante aspecto desta descontinuidade pode ser observado no processo de esvaziamento do tempo e do espaço, o qual opera naquilo que vai resultar no desencaixe das instituições sociais $(23)^{14}$.

Conforme podemos observar na citação no início deste ensaio, Giddens identifica no ator/sujeito um indivíduo dotado de considerável capacidade reflexiva, e aqui reside, em parte, a problemática tratada pelo autor ao longo do texto. Processos como a globalização, por

\footnotetext{
14 Estas questões são tratadas de modo mais aprofundado pelo autor em As Conseqüências da Modernidade (São Paulo, Editora da Universidade Estadual Paulista, 1991).
} 
exemplo, aproximam as pessoas com relação aos riscos que correm e outras conseqüências, tais como

"uma atitude calculista em relação às possibilidades de ação, positivas e negativas, com que somos continuamente confrontados, como indivíduos e globalmente em nossa existência social contemporânea" (33).

A associação entre os conceitos de modernidade e identidade se justifica por conta de um contínuo processo de organização psíquica em que o indivíduo é frequentemente instado a cultivar novos sentidos para o "eu", como ocorre, por exemplo, no divórcio. Assim, o eu se torna um projeto reflexivo (37), pautado pelo interesse em estabelecer níveis aceitáveis de segurança ontológica que consigam vencer a ansiedade do indivíduo no trato com a organização social e que lhe tragam respostas para questões de ordem existencial que são colocadas pela alta modernidade.

Com vistas a discutir uma trajetória do eu (70), Giddens volta-se para a análise de obras de auto-ajuda ${ }^{15}$. Estes cumpririam a função de estabelecer parâmetros de comportamento para os indivíduos que conferissem a estes um caminho mais seguro, do ponto de vista ontológico, e mais previsível, do ponto de vista das relações e do trato do e com o corpo, por exemplo. A vantagem estaria em destituir o indivíduo da "necessidade" de ter que tomar decisões, ao mesmo tempo em que fornece um "manual” de navegação segura em termos relacionais. A auto-identidade exige a construção de narrativas que são claramente explicitadas pelas obras de auto-ajuda.

Segundo Giddens, uma das características marcantes da alta modernidade é representada pelo risco, associado às noções de sina e destino, as quais, paradoxalmente não desaparecem na contemporaneidade. Os riscos dão conta dos perigos a que estão expostos os indivíduos nos processos de relação com outras realidades sociais construídas pela modernidade, bem como com outros indivíduos. Considerando seu potencial reflexivo, o indivíduo busca diminuir os riscos a que está exposto por meio de casulos protetores, entre os

\footnotetext{
${ }^{15}$ Merton já nos deu alguns indicativos da importância deste tipo de literatura para a formatação de um ethos de aceitabilidade das condições existenciais e de vida social (MERTON, Robert King. Sociologia - Teoria e Estrutura. São Paulo, Editora Mestre Jou, 1972. Capítulo VI, Estrutura Social e Anomia.).
} 
quais a rotina é um dos mais significativos. Fugir à rotina é se expor de modo mais franco aos riscos existentes.

O casulo protetor é a cobertura de confiança que torna possível sustentar uma Umwelt (rotina) viável. Esse substrato de confiança é condição e resultado da natureza rotinizada de um mundo "sem incidentes" - um universo de eventos reais e possiveis que cercam as atividades e projetos do indivíduo para o futuro, em que o grosso do que acontece não tem conseqüências para a pessoa de que se trata (122).

iv. Conclusão: Nós e as redes

À guisa de conclusão, uma breve análise sobre o papel representado pelas redes sociais no processo de configuração de novas identidades do indivíduo no interior da contemporaneidade descrita por Giddens, na qual há um visível deslocamento de pontos de interesse e onde as realidades vão se sobrepondo, como em camadas, retirando do indivíduo a capacidade de se localizar com precisão no tempo e no espaço, e onde a busca por identidades passa pela adoção de novas estéticas e padrões de consumo que se afirmam como os ícones deste novo tempo.

As redes sociais erigiram um novo sentido para o conceito de comunidade, longe daquele prescrito por Tönnies (1850-1936) ${ }^{16}$, e até então, aceito como legítimo por grande parte dos sociólogos, desde Robert Redfield (1897-1958) e Talcott Parsons (1902-1979). O que ora vemos e aceitamos como "comunidade", diz respeito muito mais a grupos de interesse, nos quais as relações sociais se estabelecem e se desconfiguram (para usar um termo próximo ao fenômeno) ao sabor da velocidade da time line do Facebook. O evidente descompasso entre as redes e a vida real, transformou as primeiras em espaços onde o narcisismo de todas as espécies, desde o narcisismo estético ao narcisismo intelectual, abriram espaço para uma cultura do ódio e da intolerância. Os nós das redes se fazem e se desfazem com rapidez fugaz e o que hoje aparece entre os "top trend”, amanhã é sequer citado.

16 TÖNNIES, F. Community and Society. New Jersy (EUA), TransAction Publisher, 1988. 
Neste cenário, construiu-se um novo espaço para a discussão, a conceituação e a vivência da democracia. Deve-se questionar, se haveria aqui espaço para o indivíduo reflexivo preconizado por Giddens, sabedor e conhecedor de sua realidade social e política. No mais das vezes, o que se observa é uma não criticidade em relação aos "posts" e a não aceitação de opiniões divergentes. Posso, como diz Bauman, deletar, com um simples toque, aqueles que pensam de modo diferente de mim e, incrivelmente, esse pode ser o meu entendimento do que é a democracia.

v. Bibliografia

BAUMAN, Z. O Mal-Estar da Pós-Modernidade. Rio de Janeiro, Jorge Zahar Editor, 1998. As redes sociais ão armadilhas (http://brasil.elpais.com/brasil/2015/12/30/cultura/1451504427_675885.html)

GIDDENS, Anthony. A Constituição da Sociedade. São Paulo: Martins Fontes, 1989. As Consequências da Modernidade. São Paulo: Ed. Unesp, 1991. Para Além da Esquerda e da Direita - O Futuro da Política Radical. São Paulo: UNESP, 1995. A Modernização Reflexiva - Política, Tradição e Estética na Ordem Social. São Paulo: UNESP, 1997.

Capitalismo e Moderna Teoria Social - Uma análise das obras de Marx, Durkheim e Max Weber. Lisboa: Editorial Presença, 2000.

Um Mundo em Descontrole. São Paulo: Ed. Record, 2000.

GIDDENS, A \& PIERSON, C. Conversas com Anthony Giddens - O sentido da modernidade. Rio de Janeiro: FGV, 2000.

MERTON, Robert King. Sociologia - Teoria e Estrutura. São Paulo, Editora Mestre Jou, 1972. Capítulo VI, Estrutura Social e Anomia.

MILLER, D. Deliberative Democracy and Social Choice. Political Studies, August 1992, Vol. 40, N. 1, 54-67.

TÖNNIES, F. Community and Society. New Jersy (EUA), TransAction Publisher, 1988. 